\title{
LITOESTRATIGRAFIA, SISTEMAS DEPOSICIONAIS E ICNOFÓSSEIS DO GRUPO CAACUPÉ, (ORDOVICIANO DA BACIA DO PARANÁ) NA CORDILHEIRA DE LOS ALTOS, PARAGUAI ORIENTAL
}

\author{
RENATO PAES DE ALMEIDA, CLÁUDIO RICCOMINI, LILIANE JANIKIAN, \\ ANTÔNIO ROMALINO SANTOS FRAGOSO-CESAR \& VICTOR FERNANDES VELÁZQUEZ
}

\begin{abstract}
LITHOSTRATIGRAPHY, DEPOSITIONAL SYSTEMS AND ICHNOFOSSILS OF THE CAACUPÉ GROUP (ORDOVICIAN OF THE PARANÁ BASIN) IN THE CORDILLERA DE DOS ALTOS, EASTERN PARAGUAY The Caacupé Group is composed of sandstones and conglomerates of presumable Ordovician age cropping out in the uplifted areas in the vicinity of the Assunción Rift, Eastern Paraguay. This group is considered to be the lowermost unit of the Paraná Basin, deposited prior to the glaciation registered in the lapó Formation in Brazil, and thus representing the onset of the Ordovician-Silurian subsidence cycle of the basin. Stratigraphic and lacies analyses of representative outcrops of the unit, mainly in the Cordilhera de los Altos region, have led to the revision of its formal lithostratigraphy and paleogeographic interpretation. This paper maintain the original lithostratigraphic subdivision of the Caacupé Group. This division considers two formations: Paraguarí (lower conglomerates and pebbly sandstones) and Piribebui (upper cross-stratified sandstones and pelitic lenses), the latter abandoned without proper justification. Eleven facies are described and interpreted, leading to the characterization of a westwards flowing braided river paleosystem for the conglomeratic succession (Paraguari Formation), and a nearshore depositional paleosystem dominated by tidal bars migrating towards the northwest (ebb currents) for the sandy succession (Piribebui Formation). An abundant ichnofauna supports the interpretation of a coastal origin for the Piribebui Formation and brings additional sedimentological information. The interpreted depositional systems suggest a wide sedimentary basin devoid of proximal tectonically active margins during the deposition of the Caacupé Group, a general characteristic of the subsequent Paleozoic subsidence cycles of the basin.
\end{abstract}

Keywords: Paraná Basin, Ordovician, Caacupé Group, depositional system, ichnofossils, Paraguay

Resumo O Grupo Calacupé é composto por arenitos e conglomerados de idade supostamente ordoviciana que afloram principalmente nos flancos do Rifi de Assunção, porção central do Paraguai Oriental. É considerado a mais antiga unidade da Bacia do Paraná. anterior à glaciaçẫo registrada pela Formaçẫo lapó (Brasil), e representa a base do ciclo de subsidência ordoviciano-siluriano dessa bacia intracratônica. Levantamentos estratigráficos e análise de fácies sedimentares realizados nas principais exposições da unidade, principalmente nas escarpas da Cordilheira de Los Altos, levaram a uma revisão da subdivisão litoestratigráfica formal da unidade e permitiram a interpretação de um quadro paleogeográfico com importantes implicações para o entendimento do primeiro ciclo de subsidência da Bacia do Paraná.

A presente proposta retoma a subdivisão litoestratigráfica original do Grupo Caacupé, considerando duas formações: Paraguarí (conglomerados e arenitos conglomeráticos basais) e Piribebui (arenitos com estratificação cruzada e lentes pelíticas), este último termo abandonado, sem justificativa válida, em trabalhos posteriores.

Onze lácies sedimentares são descritas e interpretadas, levando à caracterização, para a sucessão conglomerática, de um sistema de rios entrelaçados com paleofluxo para oeste e, para a sucessão arenítica sobreposta, um sistema costeiro dominado por barras de infra-maré com paleocorrentes dominantes para noroeste (vazante). A identificação de uma abundante icnofauna, relacionada às barras de inframaré da Formação Piribebui, corrobora a interpretação de uma origem marinha/transicional para a unidade e traz elementos adicionais para as interpretações sedimentológicas.

As características dos sistemas deposicionais interpretados sugerem uma bacia de área ampla, sem bordas proximais tectonicamente ativas, revelando um quadro paleogeográfico semelhante ao dos demais ciclos de subsidência da Bacia do Paraná no Paleozóico.

Palavras-chave: Bacia do Paraná, Ordoviciano, Crupo Caacupé, sistema depositional, ichnofósseis, Paraguai

INTRODUÇÃOO O Grupo Caacupé é considerado a primeira unidade da Bacia do Paraná, anterior à glaciação do final do Ordoviciano (Assine 20)() registraida na Formação Iapó (Brasil) e possivelmente correlato à Formação Alto Garças (de Assine et al. 1994) no Brasil (Milani 1997, Percira 2000), Assine 1996 e Moreira \& Borghi 1999). O grupoé composto por arenitos e, em menor medida, conglomerados, que afloram principalmente nos altos estruturais no entorno do Rift de Assunçẫo (DeGraff 1985).

A divisão estratigráfica atualmente aceita para o Grupo Caacupé foi proposta por Harrington (1972), que considerou três formações, da base para o topo: Paraguarí (conglomerados e arenitos conglomeráticos), Cerro Jhú (arenitos finos a médios, feldspáticos, por vezes com grânulos) e Tobatí (quartzo-arenitos finos, sacaroidais). A maior parte dos trabalhos existentes sobre a unidade admite uma espessura de 700 a $800 \mathrm{~m}$ para todo o grupo (e.g. Harrington 1950, 1956, 1972, Eckel 1959, Orué 1998).

Tido como afossilífero (Wolfart 1961, Putzer 1962), o Grupo Caacupé é sobreposto por folhelhos e arenitos da Formação Vargas Peña (base do Grupo Itacurubí), caracterizada por uma fauna marinha inicialmente atribuída ao Devoniano (Harrington 1950), porém considerada como llandoveriana (início do Siliuriano) desde Wolfart (1961). A correlação da Formação Vargas Peña com a 
Formação Vila Maria (e.g. Assine 1996) do Brasil, com a qual apresenta semelhanças litológicas e de conteúdo fossilífero, sugere a existência de uma superfícic relacionada à glaciação landoveriana entre o Grupo Caacupé e o Grupo Itacurubí sobreposto. Essa superfície seria correlacionada à base da Formação Iapó (tilitos), que se encontra sotoposta à Formação Vila Maria no Brasil. Orué (1998) reconheceu tilitos relacionados a esta glaciação na região de Eusébio Ayala, denominados Formação Boquerón e posicionados na base do Grupo Itacurubí.

O presente trabalho consiste na descrição das fácies sedimentares, na interpretação dos sistemas deposicionais e na caracterização dos icnofósseis do Grupo Caacupé, baseadas em estudos realizados nas principais exposições da unidade, principalmente nas escarpas da Cordilheira de Los Altos (Fig. 1). Tais estudos levaram a uma revisão das propostas litoestratigráficas e permitiram a interpretação de um quadro paleogeográfico com importantes implicações para o entendimento do primeiro ciclo de subsidência da Bacia do Paraná.

TRABALHOS ANTERIORES Como regra, as descrições e análises do Grupo Caacupé foram realizadas dentro de trabalhos mais gerais sobre a geologia de todo Paraguai Oriental (e.g. Harrington 195(). Eckel 1959, Putzer 1962, Orué 1998), sendo raros os trabalhos específicos, principalmente relacionados a mapeamento geológico básico de áreas reduzidas (e.g. Núñez et al. 1998a, b).

O nome Caacupé, derivado de uma cidade a aproximadamente $60 \mathrm{~km}$ a leste de Assunção, na porção central do Paraguai Oriental, foi inicialmente utilizado por Harrington (1950) para designar uma unidade supostamente siluriana de arenitos e conglomerados. A Série Caacupé, como inicialmente definida, foi dividida em uma unidade inferior de conglomerados, com aproximadamente $50 \mathrm{~m}$ de espessura, denominados Conglomerados Paraguarí, e uma unidade superior de arenitos, com aproximadamente $650 \mathrm{~m}$ de espessura, designada Arenitos de Piribebui. Harrington (1950) reconheceu um padrão granodecrescente na Série Caacupé, acompanhado por uma passagem de arenitos feldspáticos para arenitos quartzosos sacaroidais em direção ao topo. Harrington (1956) passou a empregar o termo Grupo Caacupé, mantendo sua subdivisão. A suposição de uma idade siluriana baseou-se na identificação de uma fauna marinha em dois afloramentos, isolados da área tipo da unidade, que o autor atribuiu à porção mediana dos Arenitos de Piribebui. Tais afloramentos foram posteriormente atribuídos ao Grupo Itacurubí, que se sobrepõe ao Grupo Caacupé (Wolfart 1961, Harrington 1972).

Eckel (1959) reconheceu um significado estratigráfico na

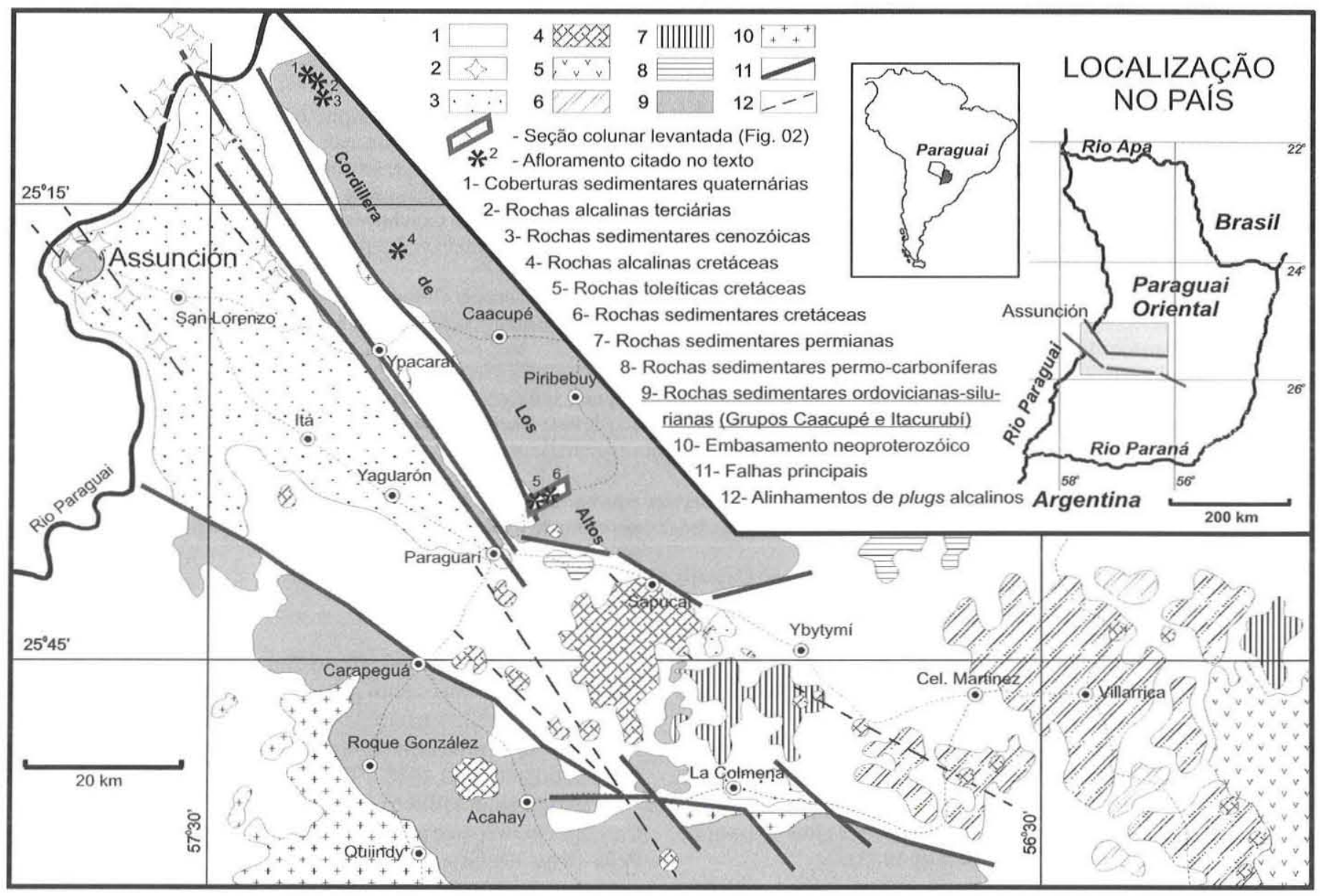

Figura I - Contexto geológico da área estudada: exposições das unidades ordovicianas-silurianas (grupos Cacıcupé e Itacurubí) nas ombreiras do Rifi de Assunção (modificado de Velázquez et al. 1998). 
passagem de arcóseos para quartzo-arenitos sacaroidais, porém designou as unidades com termos inválidos, sem referências geográficas. $\mathrm{O}$ autor aceitou a estratigrafia proposta por Harrington (1950), mas discordou da posição estratigráfica dos afloramentos fossilíferos, que considerou como superiores aos quartzo-arenitos sacaroidais, porém ainda inclusos na Série Caacupé.

Wolfart (1961) estudou os depósitos eopaleozóicos do Paraguai, estabelecendo a idade do Grupo Itacurubí como Ilandoveriana (início do Siluriano). O autor considerou o Grupo Caacupé como afossilífero, sugerindo uma idade ordoviciana ou llandoveriana para a unidade.

Putzer (1962) descreveu os conglomerados inferiores como compostos por seixos de diversas litologias, incluindo quartzitos, riolitos e mica-xistos. $\mathrm{O}$ autor considerou uma passagem gradual dos conglomerados para os arenitos sobrepostos, por eles designados de Arenitos de Caacupé.

Bigarella \& Comte (1969) realizaram estudos de paleocorrentes no Grupo Calacupé, obtendo um vetor de transporte médio para WNW, com grande consistência nas medidas obtidas em estratificações cruzadas. Como o transporte deu-se em direção ao arco Rio Apa- San Juan Bauptista, os autores consideraram uma ligação pretérita entre as bacias do Gran Chaco e do Paraná, tendo o arco soerguido em épocas posteriores. Consideraram as sucessões arenosas com estratificação cruzada como de origem marinha costeira.

Harrington (1972) propôs a divisão do Grupo Caacupé em três formações: Paraguarí (conglomerados inferiores), Cerro Jhú (arenitos feldspáticos por vezes com grânulos) e Tobatí (arenitos quartzosos sacaroidais). O autor alirmou que os afloramentos fossilíferos, por ele anteriormente atribuídos à Série Caacupé (Harrington 1950) e considerados como a unidade superior desta série por Eckel (1959), seriam parte do Grupo Itacurubí sobreposto.

Orué (1998), em ampla revisão dos trabalhos sobre a geologia do Paraguai Oriental, reiterou a litoestratigrafia de Harrington (1972) para o Grupo Caacupé, porém reviu a subdivisão do Grupo Itacurubí, descrevendo uma unidade de tilitos em sua base, anterior às camadas fossilíferas da Formação Vargas Peña.

Além desses trabalhos sobre a geologia do Paraguai, alguns autores brasileiros abordaram, em diferentes graus de detalhe, o Grupo Caacupé sob o ponto de vista da correlação com unidades mesopaleozóicas do Brasil, em trabalhos voltados à sistematização dos conhecimentos sobre a Bacia do Paraná como um todo (e.g. Milani 1997, Milani \& Ramos 1998), ou sobre as unidades devonianas e pré-devonianas dessa bacia (e.g. Assine et al. 1994, 1998, Assine 1996, Pereirat et al. 1998, Pereira 2000).

Assine et al. (1994) formalizaram o Grupo Rio Ivaí, composto, da base para o topo, pelos arenitos e conglomerados da Formação Alto Garças, pelos diamictitos glaciais da Formação lapó e pelos folhelhos e arenitos marinhos da Formação Vila Maria. Consideraram o Grupo Rio Ivaí como correlato aos grupos Caacupé e Itacurubí do Paraguai, descrevendo uma discordância erosiva entre o Grupo Rio Ivaí e a Formação Furnas, esta última atribuída ao Devoniano.

Assine (1996), em revisão sobre a evolução das unidades précarboníferas da Bacia do Paraná, postulou uma ligação entre a chamada Sequiência Ordovício-Siluriana e a Orogenia Oclóica (pré-andina) e interpretou sua deposição em uma bacia marginal extensa, ligada a um oceano a oeste. Considerou o Grupo Caacupé como equivalente à Formação Alto Garças devido à correlação da Formação Vila Maria com a Formaçĩo Vargas Penã, realizada com base no conteúdo palinológico da primeira, descrito por Gray et al. (1992).

Em tese sobre a evolução tectono-estratigráfica da Bacia do Paraná, Milani (1997) reiterou as interpretações de deposição em ambiente marinho para as unidades arenosas do Grupo Caacupé (Formações Cerro Jhú e Tobatí), encontrando evidências de ação de ondas na unidade.

Milani \& Ramos (1998) associaram o ciclo ordoviciano-siluriano de subsidência da Bacia do Paraná ao evento de colisão do Terreno Pré-Cordilheira contra a margem proto-andina, denominado Orogenia Oclóica. Os autores consideram o início da deposição da Bacia do Paraná como relacionado a uma reativação transcorrente das estruturas do embasamento de direção NE, que teria gerado a denominada Supersequiencia Rio Ivaí em depocentros transtrativos, incluindo os equivalentes paraguaios do Grupo Rio Ivaí sensu Assine et al. (1994).

Pereira (2000) reconheceu um limite de seqüências entre as sucessões arenosas do Ordoviciano (Grupo Caacupé e Formação Alto Garças) e as unidades eo-llandoverianas (Grupo Itacurubí e formações Iapó e Vila Maria). O autor atribui o isolamento e os formatos alongados dos depocentros da Seqüência Ordoviciana no Brasil e no Paraguai a uma estruturação original em bacias tectônicas separadas. Com relação ao ambiente deposicional do Grupo Caacupé, Pereira (2000) interpretou os conglomerados da Formação Paraguarí como depósitos de leques proximais, e considerou um ambiente de braided delta (delta de rios entrelaçados) para a sucessão arenosa com estratificação cruzada da Formação Cerro Jhú. Nessa unidade, o autor identificou os icnogêneros Cruziana e Rusophycus. Pereira (2000) propôs, também, uma revisão da estratigrafia do Grupo Caacupé, ao sugerir o posicionamento dos arenitos da área-tipo da Formação Tobatí acima das unidades do Grupo Itacurubí, atribuindo uma idade devoniana a estes arenitos.

SUBDIVISÃOLITOESTRATIGRÁFICA A divisão aceita do Grupo Caacupé em três formações (Paraguarí, Cerro Jhú e Tobatí) foi proposta em uma redefinição formal da unidade realizada por Harrington (1972), na qual o termo Arenitos de Piribebui (Harrington 1950) foi abandonado sem uma justificativa adequada, sendo considerado "obsoleto". Os Arenitos de Piribebui incluíam toda a sucessão arenosa acima dos Conglomerados de Paraguarí, possuindo hierarquia de formação. Uma subdivisão informal posterior, efetuada por Eckel (1959), reconheceu uma unidade de arenitos feldspáticos na porção inferior e central da unidade psamítica, e uma outra unidade de quartzo-arenitos sacaroidais no topo, sendo essa a proposta formalizada por Harrington (1972). Desta forma, os termos Formação Cerro Jhú e Formação Tobatí representam a atribuição de um posicionamento estratigráfico definido para um padrão de aumento da maturidade textural e mineralógica da sucessão arenosa em direção ao topo, já reconhecido por Harrington (1950).

Novas observações realizadas principalmente na região da Cordilheira de Los Altos desfavorecem essa divisão. Em toda a sucessão estudada foi observada a recorrência de níveis de arenitos bem selecionados e quartzosos e níveis mais feldspáticos e portadores de grânulos, descaracterizando a Formação Cerro Jhú, supostamente homogênea. Em direção ao topo ocorrem arenitos mineralogicamente maturos, porém não há modificação expressiva dos litotipos, que mantêm como característica principal camadas métricas de arenitos finos a médios com estratificação cruzada, por vezes separadas por camadas centimétricas a decimétricas de arenitos finos siltosos ou siltitos esverdeados. Dessa forma, o 
critério de distinção entre as formações Cerro Jhú e Tobatí é apenas a maturidade textural, que possui significado estratigráfico duvidoso e implica em grande dificuldade de determinação do contato entre as unidades. Essa constatação, aliada à contestável proposição formal dos termos em uso, nos leva a recomendar a restituição do termo Formação Piribebui (Arenitos de Piribebui de Harrington 1950), que possui prioridade e representa melhor o conjunto dos arenitos do Grupo Caacupé, até que sua estratigrafia seja melhor detalhada.

Nas seções estudadas, o Grupo Caacupé é composto por uma unidade basal de conglomerados sustentados pelo arcabouço de seixos arredondados de quartzo de veio e quartzito (Formação Paraguari), com até $15 \mathrm{~m}$ de espessura, sobrepostos por uma sucessão inicialmente granodecrescente de arenitos médios a finos com estratificação cruzada, quantidades variáveis de feldspato e freqüentes intercalações de arenitos finos siltosos e siltitos esverdeados, aqui incluída na Formação Piribebui (Arenitos de Piribebui de Harrington 1950).

Na região da cidade homônima, a Formação Paraguarí apresenta-se sobre uma discordância angular com rochas vulcânicas e vulcanoclásticas neoproterozóicas da Formação Cristo Redentor e, na região de San Bernardino, por discordância litológica sobre rochas graníticas neoproterozóicas. A unidade apresenta espessura de alguns metros a dezenas de metros, tendo sido descritas espessuras de até $90 \mathrm{~m}$ em sondagens na região de La Colmena (Núñez el al. 1998b). Seu contato superior com a Formação Piribebui é transicional, caracterizado por rápida granodecrescência de conglomerados para arenitos conglomeráticos e arenitos médios a fïnos (Fig. 2).

A Formação Piribebui apresenta espessura de algumas centenas de metros, com uma seção contínua de até $200 \mathrm{~m}$ na escarpa da Cordilheira de Los Altos, e uma porção superior mal aflorante no planalto de Los Altos cuja espessura é inferida com base no mergulho das camadas para oeste, medido nas escarpas. Alguns autores admitem espessuras da ordem de 700 a $800 \mathrm{~m}$ (Eckel 1959, Harrington 1972).

\section{FÁCIESSEDIMENTARESESISTEMASDEPOSICIONAISDA FORMAÇÃO PARAGUARÍ A Formação Paraguari é caracterizada por conglomerados sustentados pelos clastos, predominantemente compostos por quartzo de veio e quartzito, com fração areia contendo feldspatos, além de arenitos grossos conglomeráticos, também feldspáticos. Os depósitos descritos podem ser classificados em três fácies sedimentares principais:}

Fácies 1 Conglomerados sustentados por seixos a matacões imbricados. Os seixos, calhaus e matacões são arredondados, com formas esféricas, oblatas e prolatas, compostos por quartzo de veio e quartzito, com diâmetros predominantemente em torno de 4 $\mathrm{cm}$, localmente alcançando mais de $25 \mathrm{~cm}$ (Fig. 3a). Predominam conglomerados maciços ou gradados, com ocorrência restrita de conglomerados com estratificação cruzada planar. Ocorrem em camadas lenticulares métricas a decimétricas, geralmente com granodecrescência ascendente, amalgamadas ou associadas a arenitos conglomeráticos da Fácies 2. A imbricação dos seixos dáse segundo o plano $\mathrm{AB}$, indicando transporte por rolamento (Walker 1975). Esta fácies é interpretada como depósitos de carga de fundo de correntes trativas, em barras conglomeráticas fluviais.

Fácies 2 Arenitos grossos a muito grossos com estratificação cruzada acanalada (Fig. 3b) e, mais restritamente, estratificação cruzada planar, de pequeno e médio porte, com freqüentes seixos e grânulos nos estratos frontais. Ocorrem em pacotes métricos ou como lentes decimétricas isoladas em meio aos conglomerados da Fácies 1. A geometria das camadas é geralmente lenticular. São interpretados como depósitos de dunas subaquáticas de cristas sinuosas (estratificação cruzada acanalada) ou de cristas retas (estratificação cruzada planar), geradas por correntes fluviais unidirecionais.

Fácies 3 Arenitos grossos a muito grossos, ocasionalmente com seixos esparsos de até $2 \mathrm{~cm}$ de diâmetro, apresentando estratificação plano-paralela. Ocorrem no topo de ciclos granodecrescentes iniciados pelos conglomerados da Fácies 1. São interpretados como depósitos de carga de fundo em leito plano, gerados por correntes trativas em regime de fluxo inferior.

Paleogeografia da Formação Paraguarí A associação de diferentes fácies arenosas e conglomeráticas interpretadas como produtos de correntes trativas unidirecionais, a abundância de geometrias lenticulares e canalizadas e a ausência de fácies diagnósticas de leques aluviais, como lamitos seixosos de fluxo de detritos e camadas conglomeráticas pareadas com variação granulométrica, formadas em enchentes em lençol (Blair \& McPherson 1994), sugerem um ambiente fluvial de rios dominados por carga de fundo cascalhenta, possivelmente com canais entrelaçados separados por barras longitudinais. As fácies conglomeráticas apresentam maturidade mineralógica e textural elevada, com proveniência dos seixos quase que exclusivamente de quartzo leitoso e quartzito, revelando intensa seleção mineralógica, relacionada talvez ao clima, mas certamente associada a longas distâncias de transporte em um ou mais ciclos de sedimentação. Assim, as características faciológicas da Formação Paraguarí são incompatíveis com a interpretação de sistemas de leques aluviais ou sistemas de alta energia drenando fontes proximais relacionadas a falhas de borda. As paleocorrentes, indicadas pelas fácies de arenitos com estra-tificação cruzada, apresentam boa consistência e sentido de trans-porte para oeste (Fig. 3c), como constatado por Bigarella \& Comte (1969). Tais paleocorrentes vão em direção à atual borda oeste da bacia, sugerindo a inexistência desta borda ao tempo da deposição do Grupo Caacupé, como proposto por Bigarella \& Comte (1969), Assine (1996) e Assine et al. (1998). A paleogeografia deste sistema aluvial provavelmente constituía uma planície de rios entrelaçados relacionada a uma ampla bacia de drenagem, em uma área com relevo pouco acentuado, compatível com uma bacia sedimentar intracratônica com grande área de subsidência.

FÁCIESSEDIMENTARESESISTEMASDEPOSICIONAISDA FORMAÇÃO PIRIBEBUI A Formação Piribebui caracteriza-se pelo predomínio de camadas decimétricas lenticulares de arenitos finos claros, moderadamente friáveis, pouco cimentados e por vezes feldspáticos, com estratificação cruzada tabular tangencial na base e, localmente, estratificação plano-paralela. Camadas milimétricas a centimétricas de pelitos muitas vezes intercalam-se às camadas areníticas, que comumente apresentam icnofósseis em hiporrelevo positivo em seus contatos inferiores com os pelitos. Foram identificadas as seguintes fácies sedimentares na unidade:

Fácies 4 Arenitos finos, médios e grossos com estratificação cruzada tabular, frequientemente tangencial na base, constituindo camadas predominantemente lenticulares de espessuras 


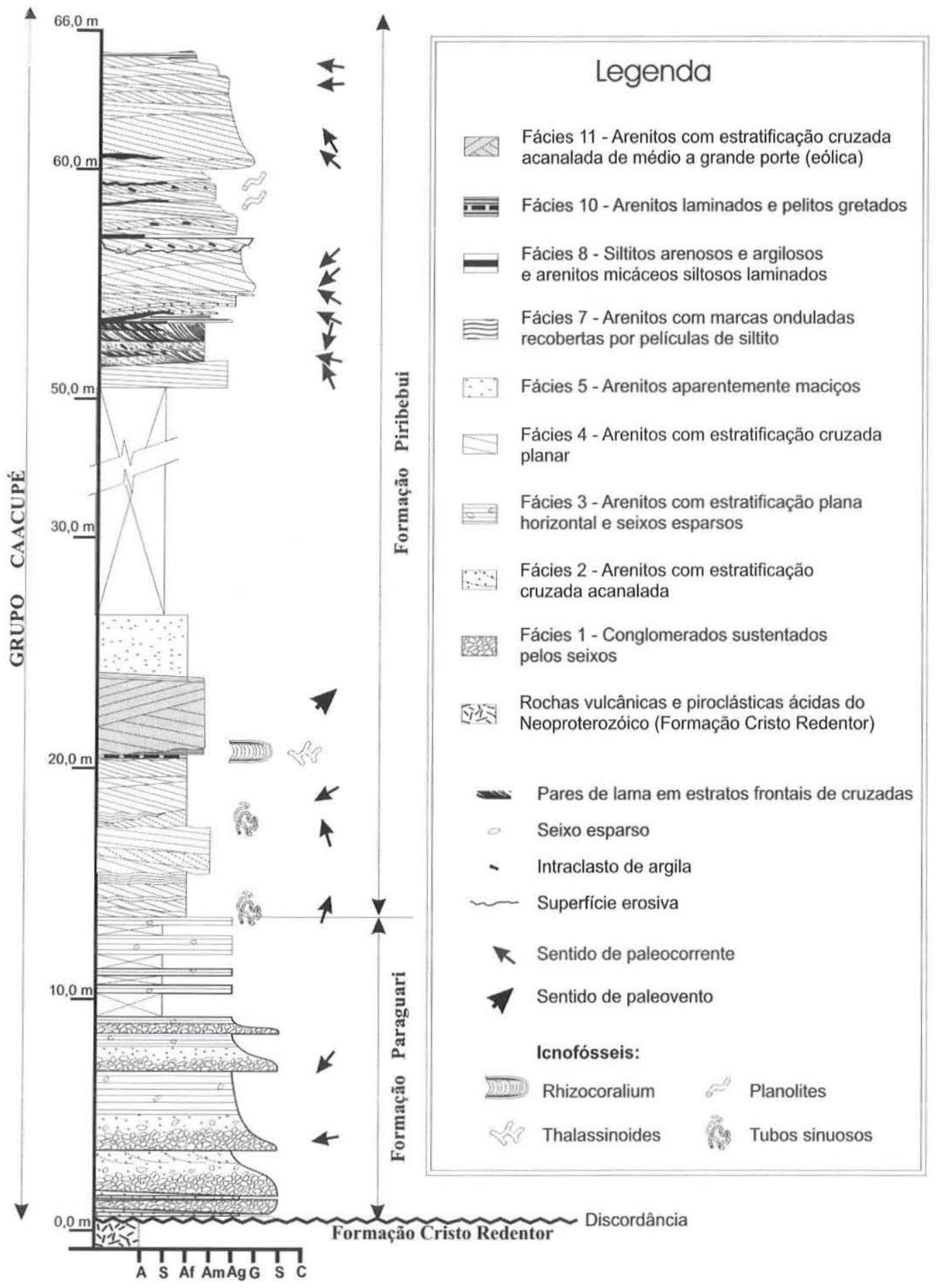

Figura 2 - Seção colunar da Formação Paraguarí e da porção inferior da Formação Piribebui na Cordilheira de Los Altos, ver localização na figura 1.

decimétricas a métricas. Ocorrem níveis com seixos esparsos ou intraclastos argilosos na base das camadas, que por vezes passam lateralmente para estratos centimétricos a decimétricos de arenitos com marcas onduladas (fácies 7), relacionados a siltitos arenosos ou arenitos muito finos com bioturbações (fácies 8). A presença de superfícies de reativação (superfícies erosivas com mergulho pouco menor do que a atitude dos estratos frontais) nas porções superiores das camadas resulta em um perfil sigmóide para a estrutura (Fig. 4a), com terminações tangenciais no topo e na base. Localmente ocorrem abundantes películas argilosas nos estratos frontais, geralmente recobrindo superfícies de reativação. Essas películas argilosas separam lâminas ou delgadas camadas de arenitos que por vezes mostram ciclicidade, com alternância de espessuras maiores e menores, dando origem a pares de lâminas pelíticas separadas por estratos arenosos (Fig. 4b). Esse tipo de estrutura (tidal bundles) é atribuído à ciclicidade bidiária de 

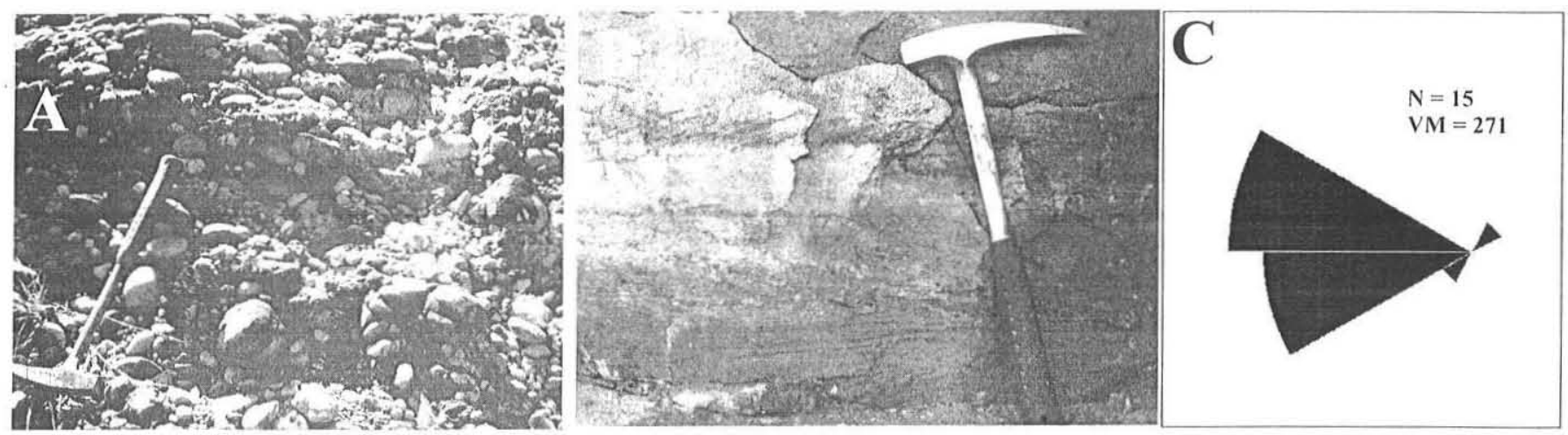

Figura 3 - Fáciés sedimentares da Formação Paraguarí. A - Conglomerados com seixos imbricados (fácies 1), afloramento 5 da figura I. B - Arenitos conglomeráticos com estratificação cruzada acanalada (fácies 2), afloramento 5. C - Paleocorrentes aluriais da Formașão Paraguarí, com vetor médio para oeste. $N=$ mímero de medidas, V.M. = azimute do vetor médio.

correntes de maré, sendo considerado por alguns autores como um dos melhores indícios de ação de marés em depósitos antigos (Visser 1980).

A fácies 4 compõe a maior parte da sucessão da Formação Piribebui e é interpretada como o resultado da migração de dunas subaquáticas de cristas retas (sand waves), pela ação de correntes de marés fortemente assimétricas. A deposição de lâminas pelíticas reflete períodos de estagnação entre os eventos de deposição de camadas arenosas, estas formadas pela corrente dominante por avalanche na frente da duna. A alternância de camadas arenosas mais espessas e menos espessas é reflexo da diferença de intensidade entre as duas marés em um ciclo bidiurno. A corrente subordinada, com sentido oposto ao da dominante e energia insuficiente para gerar grandes formas de leito, foi provavelmente responsável pela formação das superfícies de reativação.

Fácies 5 Arenitos linos, aparentemente maciços, com seleção granulométrica moderada a boa, constituindo camadas lenticulares, de espessura centimétrica a decimétrica, associadas aos arenitos da fácies 4. A aparente ausência de estruturas internas pode ser resultado de dificuldade de observação devido à boa seleção granulométrica, porém não se descarta a possibilidade de obliteração de estruturas preexistentes por liquefação ou mesmo bioturbação.

Fácies 6 Arenitos finos a médios com estratificação cruzada composta, com estratos cruzados de médio a grande porte, langenciais na base, contendo abundantes laminações cruzadas ou mesmo estratificações cruzadas tabulares internas aos estratos cruzados maiores (Fig. $4 \mathrm{c}$ ). Ocorrem associados à fácies 4, por vezes em séries limitadas no topo e na base por delgadas camadas de pelitos (fácies 8). A geometria das camadas em corte é lenticular a tabular. As espessuras variam de 1,5 a mais de $10 \mathrm{~m}$. A relação entre a atitude dos estratos cruzados e o sentido das laminações cruzadas que contém geralmente é de obliqüiidade a altos ângulos ou mesmo de oposição.

Esta fácies, que ocorre apenas nas porções superiores da sucessão estudada, é interpretada como resultado da migração de barras arenosas complexas, com padrões de acréscimo lateral ou frontal, em ambiente de infrat-maré. Direções opostas de laminações cruzadas são interpretadas como produto de correntes opostas de maré, e sua superposição em estruturas maiores é interpretada como indício da grande variação de energia da corrente.

Fácies 7 Arenitos finos a muito finos, com marcas onduladas recobertas por películas de siltito ou argilito, por vezes relacionadas a laminação cruzada cavalgante, dispostos em camadas centimétricas tabulares a lenticulares. Ocorrem associados à fácies 4, como extensão lateral da base tangencial dos estratos frontais, na transição para a fácies 8 . Tal relação geométrica com as fácies 4 e 8 sugere uma origem relacionada à migração de pequenas formas de leito nas regiões mais profundas entre as barras de inframaré, sendo cada estrato arenoso separado por um depósito de decantação de maré estofa.

Fácies 8 Siltitos argilosos ou arenosos e arenitos muito finos siltosos, laminados, de coloração esverdeada, em camadas lenticulares a tabulares centimétricas que separam conjuntos de arenitos com estratificação cruzada (fácies 4 e 6), raramente compondo camadas decimétricas tabulares. Freqüientemente ocorrem em continuidade lateral com a porção tangencial inferior de estratos cruzados de arenitos. São interpretados como depósitos de material fino na zona de infra-maré, no substrato entre as dunas e barras compostas, onde a expansão do fluxo limita a capacidade de transporte da corrente e permite a acumulação dos depósitos de decantação dos episódios de estagnação (maré estofa).

Fácies 9 Arenitos finos a médios com estratificação cruzada tipo swaley, caracterizada por cruzadas de pequeno porte e baixos ângulos, preenchendo escavações rasas, decimétricas, côncavas para cima (Fig. 4d) e com formas circulares a elípticas em planta. Ocorrem isoladamente em camadas decimétricas irregulares com base escavada, geralmente granodecrescentes, associadas às fácies de dunas subaquáticas (fácies 4 e 6), ou em raras camadas amalgamadas em associação com estratificação cruzada tipo hummocky. Esta fácies, pouco frequiente, é interpretada como o produto da ação de ondas, com efeito erosivo irregular devido ao caráter oscilatório do fluxo, e preenchimento ainda sob a ação da oscilação. Essas características sugerem ondas de tempestade retrabalhando episodicamente a zona de infra-maré.

Fácies 10 Arenitos finos a médios com estratificação planoparalela, associados a arenitos com marcas onduladas simétricas e assimétricas de cristas retas. Localmente ocorrem lâminas 

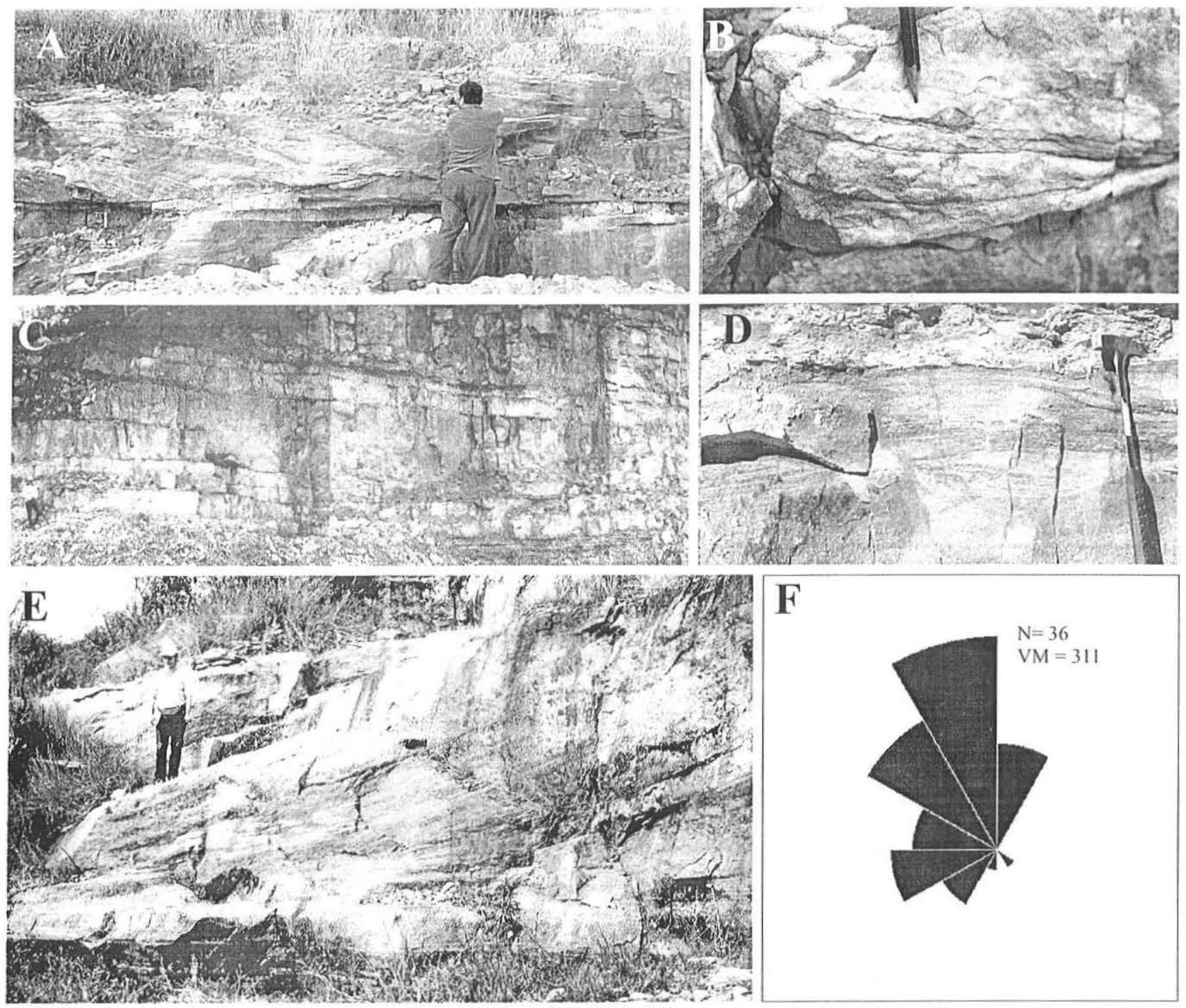

Figura 4 - Fácies sedimentares da Formação Piribebui. A - Arenitos com estratificação cruzada planar: tangencial no topo e na base (sigmöide), fácies 4, aftoramento 4 da figura. I. B-Arenitos com tidal bundles, fácies 4 (notar pares de películas argilosas nos estratos firontais), afloramento 2. C - Arenitos com estratificaşão cruzada composta, fácies 6, afloramento I (notar camadas inclinadas para a direita, separadas por camadas de pelitos e contendo estratificação cruzada interna), pessoa no canto infeiror esquerdo como escala. D - Arenitos com estratificação cruzada tipo swaley, fácies 9, afloramento 4. E-Arenitos eólicos com estratificação cruzada, afloramento 6. F- Paleocorrentes medidas em estratificações cruzadas das fácies 4 e 6, mostrando transporte para $N W$ nas barras de marés. $N=$ múmero de medidas, $V . M .=$ azimute do vetor médio.

pelíticas, por vezes com gretas de contração. Os arenitos laminados e com marcas onduladas são interpretados como depósitos de correntes trativas respectivamente em leito plano e em pequenas formas de leito em regime de fluxo inferior: As evidências de exposição subaérea ocasional sugerem águas muito rasas, indicando um ambiente de intermaré. Esta fácies ocorre de forma limitada, em conjunto de espessura métrica entre uma sucessão dominada pelas fácies 4,6 e 8 e pequeno pacote da fácies 11 .

Fácies 11 Arenitos finos a médios com estratificação cruzada de grande porte e alto ângulo (Fig. 4e), composta por intercalações de estratos maciços lenticulares (fluxo de grãos) e estratos laminados (chuva de grãos), com a presença também de fácies de migração de marcas onduladas eólicas. Essas intercalações geram padrões de variação de granulometria e empacotamento que se refletem nas exposições pela alteração diferencial, gerando sulcos do tipr, pin stripe (Fryberger \& Schenk 1988). Esta fácies, já reconnecida por Pereira (2000), é interpretada como produto da migração de dunas eólicas em planície costeira e ocorre em camada de poucos metros de espessura, imediatamente sotoposta ao pacote da fácies 10 acima descrito. Este único nível descrito da fácies 11 define o topo de um grande ciclo dominado pela fácies 4 , e caracteriza um limite de sequiências deposicionais.

Paleogeografia da Formação Piribebui O conjunto das 
fácies identificadas na Formação Piribebui sugere um predomínio de condições marinhas rasas, em ambiente dominado por correntes de maré. O predomínio de formas de leito decimétricas a métricas com sentido de migração consistente para NW (Fig. 4f) sugere que a corrente dominante foi a de vazante, aproximadamente paralela ao paleofluxo lluvial obtido para a Formação Paraguarí. A presença de depósitos eólicos em meio a uma sucessão de fácies costeiras evidencia um evento de recuo brusco da linha de costa, relacionado a rebaixamento do nível de base, que limita duas sequiências deposicionais. Estudos detalhados das porções superiores da Formação Piribebui podem revelar a recorrência de tais eventos.

A grande continuidade lateral e a persistência vertical dos depósitos sugerem uma costa linear, sem a grande variedade e a complexa interação entre ambientes deposicionais que caracterizam sistemas estuarinos. O padrão retrogradacional a agradacional da sucessão medida (Fig. 2) e a ausência de depósitos fluviais ou de distributários deltaicos nas porções superiores, mesmo nas proximidades do limite de sequiências, desfavorece a interpretação de um sistema de deltas de rios entrelaçados, que poderia explicar a transição entre as formações Paraguarí e Piribebui (Pereira 2000).

ICNOFÓSSEIS Um dos principais elementos utilizados na reconstituição paleogeográfica do Grupo Caacupé foi a identificação de uma vasta icnofauna nos arenitos da Formação Piribebui, que contribuiu para a confirmação de um ambiente costeiro para esta unidade e forneceu elementos importantes para a interpretação de processos de sedimentação. Trabalhos anteriores restringiam-se à menção da presença dos icnogêneros Skolithos (Orué 1998), Cruziancı e Rusophycus (Pereira 2000).

Foram encontrados icnofósseis em abundância, principalmente relacionados à icnofácies cruziana (Seilacher 1967, Pemberton et al. 1992), associados às camadas de siltitos e arenitos siltosos (fácies 8) intercaladas às barras de infra-maré (fácies 4 e 6), e subordinadamente da icnofácies skolithos (Seilacher 1967. Pemberton et al. 1992), associados a topos de barras de maré e fácies de retrabalhamento por fluxo oscilatório (fácies 9).

A porção basal da Formação Piribebui é caracterizada pela presença de Cruziana formada no topo de camadas de pelitos que separam barras arenosas de infra-maré. Considera-se um modelo deposicional em que as dunas e barras complexas migram sobre depósitos de suspensão formados nas depressões entre as barras, onde os organismos alimentavam-se do conteúdo orgânico dos pelitos da fácies 8 (Fig. 5). Uma outra associação desta porção inferior é representada por formas dos icnogêneros Rhizocorallium e Thalassinoides e por tubos sinuosos em epirrelevo positivo, encontrados em arenitos da fácies 10, interpretados como depósitos de intermaré inferior.

Nas porções intermediária e superior da Formação Piribebui também são abundantes formas da icnofácies cruziana relacionadas a camadas de pelitos entre barras de infra-maré. Ocorrem grandes traços isolados do icnogênero Cruziana, além de uma variada icnofauna de formas de alimentação e locomoção associadas a formas de repouso de artrópodes (provavelmente trilobitas), composta por Cruziana de grande e pequeno porte, Rusophycus e Monomorphichinus.

Em afloramento dessa porção superior, foi observada uma interessante relação entre os icnofósseis verticais, relacionados a fixação em ambiente de alta energia e alimentação a partir de material em suspensão (Skolithos), e os traços horizontais, gerados em superlície por organismos que se alimentam de material depositado. Tubos verticais, classificados como Skolithos linearis, ocorrem sobre barras arenosas de infra-maré, apenas localmente com estruturas indicativas de ação de fluxo oscilatório ou combinado, enquanto Cruziana ocorre nas camadas argilosas intercaladas, mostrando um controle relacionado à energia atuante no substrato e não necessariamente à batimetria. Situação semelhante é descrita por Mángano et al. (1996) em uma unidade cambro-ordoviciana do noroeste da Argentina, interpretada como depósitos costeiros dominados por correntes de maré.

Abaixo são descritos os principais icnofósseis encontrados, classificados em icnogêneros e, quando possível, icnoespécies.

\section{Icnogênero Cruziana d'Orbigny, 1842 \\ Cruziana isp. A}

Descrição: Pequenos traços bilobados, separados por sulco longitudinal, com 5 a $6 \mathrm{~mm}$ de largura e 1 a $2 \mathrm{~mm}$ de profundidade, preservados como hiporrelevo positivo na base de camadas de arenitos finos das fácies 4 e 6, que sobrepõem pelitos da fácies 8 . As laterais dos traços são íngrimes, por vezes verticais, não havendo sulcos externos ou lobos exopodais. As estrias endopodais são pouco preservadas, transversais a proversas. As escavações são retilíneas a sinuosas, com freqüentes cruzamentos e ocorrência em planos de acamamento dominados por Rusophycus isp., ao qual estão morfologicamente relacionadas (Fig. 6a). Esta forma é freqüente na porção superior da Formação Piribebui.

\section{Cruziana isp. B}

Descrição: Grandes traços, com 49 a 52 mm de largura e 13 a 16 $\mathrm{mm}$ de profundidade, caracterizados por dois lobos endopodais bem desenvolvidos separados por sulco longitudinal raso com 6 a $7 \mathrm{~mm}$ de largura. As estrias endopodais são irregulares, proversas, regularmente espaçadas de 2 a $3 \mathrm{~mm}$, formando ângulo $\mathrm{V}$ entre 40 e $50^{\circ}$, sem bifurcações aparentes em suas porções externas. Não ocorrem lobos exopodais ou sulcos externos e os limites dos lobos endopodais são íngremes. No exemplar descrito (Fig. 6b), um cruzamento em alto ângulo revela clara sobreposição de dois traços. Os traços são preservados como hiporrelevo positivo no contato entre arenitos médios das fácies 4 e 6 e camadas sotopostas de pelitos da fácies 8 .

\section{Icnogênero Momomorphichnus Crimes, 1970 \\ Monomorphichnus isp. A}

Descrição: Estrias simples e rasas, retilíneas, em séries paralelas com até 7 estrias espaçadas de 10 a $15 \mathrm{~mm}$ (Fig. 6c). A largura das estrias é de cerca de $0,8 \mathrm{~mm}$, com comprimento de até $65 \mathrm{~mm}$. Os traços encontram-se preservados como hiporrelevo positivo na

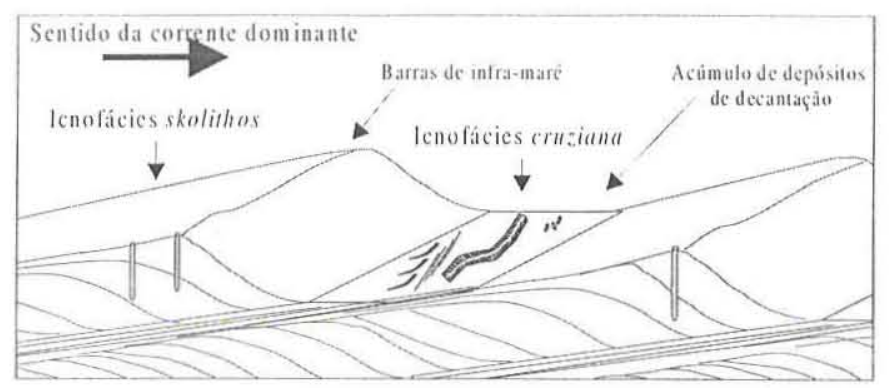

Figura 5 - Modelo deposicional das relações entre os arenitos com estratificação cruzada (fácies 4 e 6 ) e os siltitos laminados (fácies 8), considerando a distribuição das icnofácies cruziana e skolithos na Formação Piribebui. 


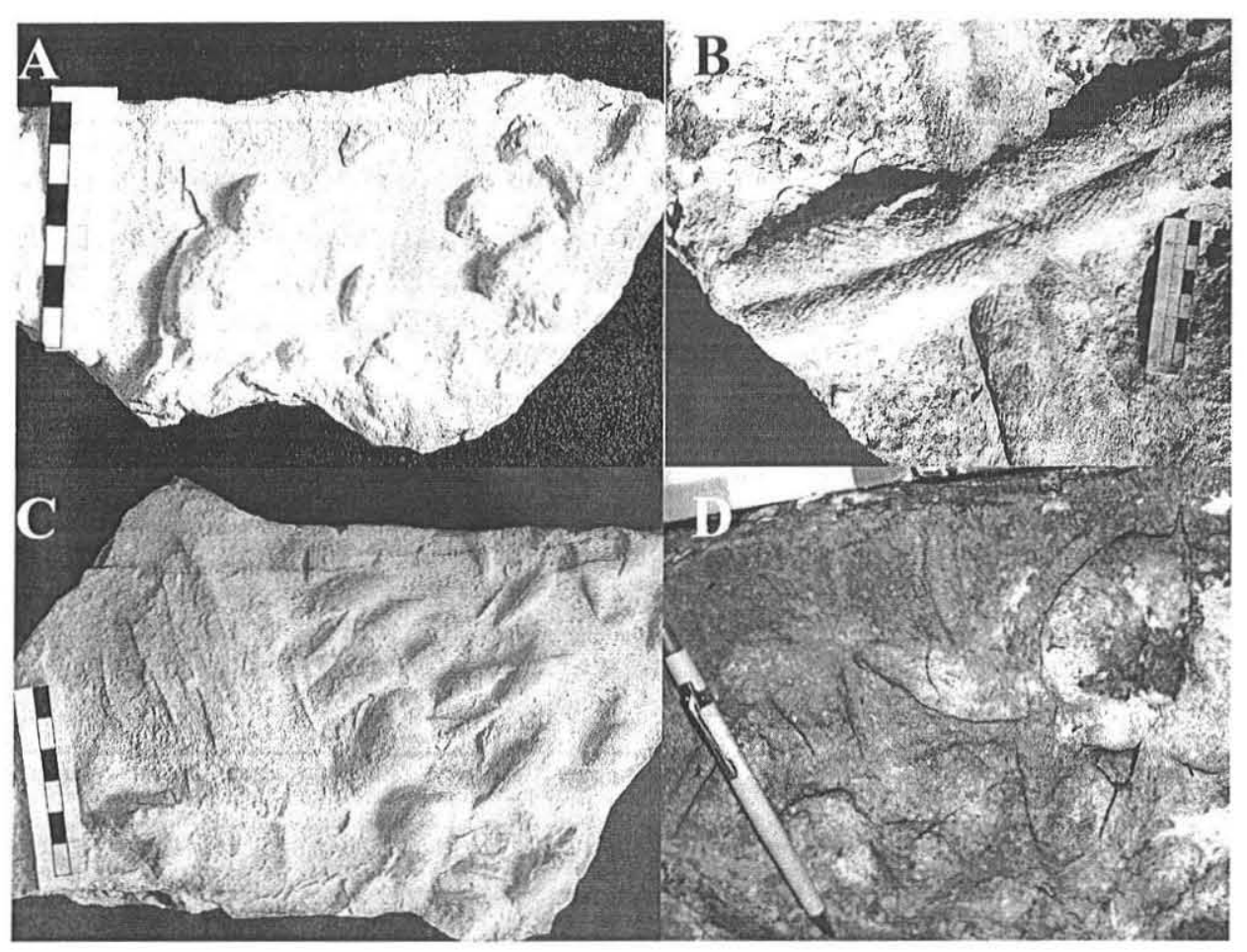

Figura 6-Icnofósseis da Formaşão Piribebui. A - Cruziana isp. A relacionada a Rusophycus isp. (centro), preservados como hiporrelevo positivo, afloramento I da figura I. Graduaçäo da escala $=6 \mathrm{~cm}$. B - Cruziana isp. B como hiporrelevo positivo, afloramento 4. Graduação) da escala $=6 \mathrm{~cm}$. C - Monomorphichnus isp A (à escuuerda) e isp. B (à direita) em hiporrelevo positivo, afloramento I. Graduação da escala $=6 \mathrm{~cm} . \mathrm{D}$ - Planolites berveleyensis em arenitos siltosos da fácies 8 , afloramento 6.

base de camadas de arenitos finos das fácies 4 e 6.

A ausência de trilhas de marcas pontuais associadas caracteriza o icnogênero Monomorphichnus, distinguindo-o de Dimorphichnus Seilacher (1955).

\section{Monomorphichnus isp. B}

Descrição: Traços horizontais retilíneos ou com forma de cunha, com comprimento de 25 a $40 \mathrm{~mm}$ e 4 a $5 \mathrm{~mm}$ de largura e, quando em cunha, largura maior de 6 a $10 \mathrm{~mm}$ e menor de 2 a $3 \mathrm{~mm}$. A profundidade é de cerca de $5 \mathrm{~mm}$. Os traços estão dispostos em séries de formas paralelas, com distância constante de 12 a 25 mm, deslocadas longitudinalmente de uma distância também constante de 10 a 16 mm (Fig. 6c). Os traços apresentam estrias longitudinais, paralelas, em número de 3 a 6 , eqüidistantes cerca de $1 \mathrm{~mm}$. A preservação dá-se como hiporrelevo positivo na base de camadas de arenitos finos das fácies 4 e 6.

\section{Icnogênero Planolites Nicholson, 1873}

Planolites beverlevensis Billings, 1862

Descrição: Tubos predominantemente horizontais, levemente curvos a retilíneos, cilíndricos ou com seção elíptica, com 7 a 10 mm de diâmetro (Fig. 6d), em pelitos arenosos e arenitos siltosos da fácies 8. Ocorrem em grande densidade em algumas superfícies, com cruzamentos e sobreposições. A superfície dos tubos é lisa, sem estrias ou ornamentação, sendo caraterizada por contato abrupto do preenchimento com a rocha envolvente, sem lineação. Os tubos são preenchidos por arenitos finos maciços, com fração pelítica escassa ou ausente, sugerindo modificação da granulação do sedimento por sua passagem pelo tubo digestivo do organismo produtor do traço. A ausência de lineação na parede do tubo e o preenchimento por material distinto daquele da rocha envolvente caracterizam, de acordo com Pemberton \& Frey (1982), o icnogênero Planolites, distinguindo-o de Palaeophycus. O grande porte, o predomínio de traços levemente curvos a retilíneos e a ausência de anulações transversais caracterizam a icnoespécie Planolites beverleyensis.

\section{Icnogênero Rhizocorallium Zenker, 1836}

Rhizocorallium cf. irregulare Mayer, 1954

Descrição: Traços horizontais formados por faixa de spreite protusivo que acompanha a forma do tubo externo que delimita o traço (Fig. 7a). Tal tubo possui forma em U e encontra-se preservado como um sulco (epirrelevo negativo), enquanto o spreite forma epirrelevo positivo com alguns milímetros de altura ou negativo com alguns milímetros de profundidade. O spreite é caracterizado por uma série de cristas amalgamadas, arqueadas de forma a tangenciar o tubo externo em suas extremidades.

Os traços são curvilíneos a retilíneos e abundantes no mesmo pavimento, sedo comuns os cruzamentos, além de algumas aparentes bifurcações. A faixa de spreite possui largura de 90 a $170 \mathrm{~mm}$ e o tubo externo, quando preservado, cerca de $10 \mathrm{~mm}$. O comprimento máximo observado foi de $2,5 \mathrm{~m}$.

A faixa de spreite e o tubo externo são caracterizados por uma granulação maior (areia média) que a dos arenitos finos aflorantes no pavimento imediatamente inferior, sendo que em alguns pontos pôde-se observar a presença de uma delgada camada de argila no mesmo nível do spreite, possivelmente a camada explorada pelos organismos produtores do traço. 
Apesar do tamanho superior ao das formas originalmente descritas, o caráter horizontal do spreite e o predomínio de formas longas e curvilíneas levariam, de acordo com a proposta de Fürsich (1974), à classificação da forma como Rhizocorallium irregulare Mayer 1954, caracterizando a ação de organismos que se alimentavam de material depositado.

\section{Icnogênero Rusophycus Hall, 1852}

Rusophycus isp.

Descriçĩo: Pequenas formas com contornos ovais, com cerca de $14 \mathrm{~mm}$ de comprimento, $6 \mathrm{~mm}$ e largura e 1,5 a $2 \mathrm{~mm}$ de profundidade, caracterizadas por dois lobos separados por sulco central raso. A forma $\mathrm{e}$ as dimensões são aproximadamente constantes em todos os exemplares, que podem ocorrer isoladamente ou em grandes grupos sem orientação preferencial (Fig. 7b), por vezes associados a Cruziana isp. A (Fig. 6a). Os limites externos dos lobos endopodais são íngremes e não puderam ser observadas estrias endopodais. Os traços encontram-se preservados em hiporrelevo positivo na base de camadas de arenitos finos das fácies 4 e 6 .

\section{Icnogênero Skolithos Haldemann, 1840}

Skolithos linearis Haldemann, 1840

Descrição: Tubos verticais com cerca de $2 \mathrm{~mm}$ de largura e até alguns decímetros de comprimento, em arenitos finos principalmente da fácies 9 , com preenchimento também de areia fina, sem estruturas aparentes. Em alguns casos (Fig. 7c) a expressão superficial da forma é preservada, caracterizada como um anel em epirrelevo positivo, com diâmetro externo de $6,5 \mathrm{~mm}$ e diâmetro interno de $2 \mathrm{~mm}$ (Fig. 7d). A coincidência entre os diâmetros do tubo e de sua expressão superficial indica a ausência de um alargamento em forma de cone em sua porção superior.

\section{Icnogênero Thalassinoides Ehrenberg, 1944}

Thalassinoides isp.

Sistema de escavações predominantemente horizontais, formado por tubos preservados como epirrelevo positivo com 5 a $8 \mathrm{~mm}$ de diâmetro. sem ornamentação, associados à fácies 10. Frequientes bifurcaçôes em T e Y, em conjunto com a grande densidade de ocorrência, resultam em um padrão poligonal para a estrutura (Fig. 7e).

Tubos sinuosos Escavações tubulares horizontais, sinuosas a meandrantes, com grande comprimento e largura constante de aproximadamente $2 \mathrm{~cm}$, preservadas como epirrelevo positivo em arenitos finos da fácies 10 (Fig. 7f). Não foram observadas bifurcações, apenas cruzamentos, muitas vezes de uma mesma pista cortando sua própria trajetória em traçados aleatórios. Os tubos não apresentam ornamentação, porém aparentemente ocorrem pequenas constriçôes, como suaves anéis transversais de diâmetro menor, irregularmente espaçados de 10 a $30 \mathrm{~mm}$, semelhantes aos encontrados em Torrowangea Webby 1970), que porém se refere a uma uma estrutura menor ( 1 a $2 \mathrm{~mm}$ de largura) preservada em hiporrelevo positivo.

CONCLUSÕES Os levantamento geológicos realizados nas principais exposições do Grupo Caacupé na região central do Paraguai Oriental levou à revisão da litoestratigrafia da unidade, bem como à interpretação de seus sistemas deposicionais e do significado tectônico de seus depósitos.
A subdivisão estratigráfica do Grupo Caacupé em três formações mostrou-se contestável, não tendo sido reconhecida a validade da divisão da sucessão arenosa da unidade em duas formações, uma feldspática (Cerro Jhú) e outra quartzo-arenítica (Tobatí). As sucessões estudadas revelaram uma alternância de arenitos mineralogicamente maturos e sub-maturos, sem conotação estratigráfica para a variação de maturidade, nem modificações expressivas dos litotipos e sistemas deposicionais. Dessa forma, sugere-se que seja retomada a designação prioritária Formação Piribebui (Harrington 1950) para a sucessão arenosa, que fora abandonada sem justificativa válida. Para a sucessão basal, conglomerática, do Grupo Caacupé, mantém-se a designação Formação Paraguarí (Harrington 1950, 1972).

A análise de fácies sedimentares levou à caracterização de um sistema deposicional fluvial de rios entrelaçados distais para a Formação Paraguarí. Para a sucessão arenítica sobreposta (Formação Piribebui), confirmou-se a interpretação de um sistema deposicional costeiro (Bigarela \& Comte 1969, Milani 1997), porém com a caracterização de amplo predomínio de fácies de infra-maré, anteriormente não reconhecidas, e ocorrência local de de tempestitos e depósitos de pós-praia (backshore) com dunas eólicas (já descritos por Pereira 2000), os últimos possivelmente decorrentes de evento de rebaixamento do nível de base.

A identificação de icnofósseis, predominantemente da icnofácies cruziana, serviu de complemento às interpretações dos ambientes deposicionais, confirmando o caráter costeiro da sucessão arenosa e auxiliando a identificação dos processos deposicionais. Foram coletados e registrados diversos espécimes, identificados como pertencentes aos icnogêneros Cruziana, Monomorphichinus, Rhizocorallium, Rusophycus, Skolithos e Thalassinoides.

As paleocorrentes fluviais da Formação Paraguarí, com vetor médio para oeste, em conjunto com os dados de paleofluxo para noroeste da Formação Piribebui, interpretados como correntes de maré vazante, corroboram a hipótese de Bigarella e Comte (1969) de inexistência do alto estrutural que hoje limita a bacia a oeste e sugerem uma conexão marinha nesse quadrante, como anteriormente proposto por Assine (1996) e Assine et al. (1998).

A hipótese de que o Grupo Caacupé teria sido formado em uma bacia distensional ou transtrativa (Milani \& Ramos 1998, Pereira 2000) baseia-se, em grande medida, na interpretação de um ambiente de leques aluviais para a Formação Paraguarí (Pereira 2000), relacionado a possíveis falhas proximais que seriam responsáveis pelas formas alongadas dos mapas de isópacas. As características dos conglomerados descritos não são, porém, compatíveis com as de depósitos de leques aluviais, pois predominam fácies de correntes trativas canalizadas, sem fácies de fluxo de detritos ou enchentes em lençol, e não há contribuição clástica proximal. Assim, não há evidências de campo que suportem a suposição de escarpas tectônicas proximais limitando a bacia. Desta forma, a paleogeografia interpretada para a Formação Paraguarí é de uma planície de rios entrelaçados relacionada a uma ampla bacia de drenagem, sugerindo sedimentação intracratônica em uma grande área de subsidência, possivelmente a primeira sinéclise da Bacia do Paraná.

Agradecimentos À FAPESP(Processos 00/11089-2,01/01439-9 e (0)/(0751()-4) pelo apoio financeiro. À Dra. Lucy Sant'Anna pelas sugestões e revisão do texto final. Aos revisores da RBG pelas sugestões ao manuscrito. 

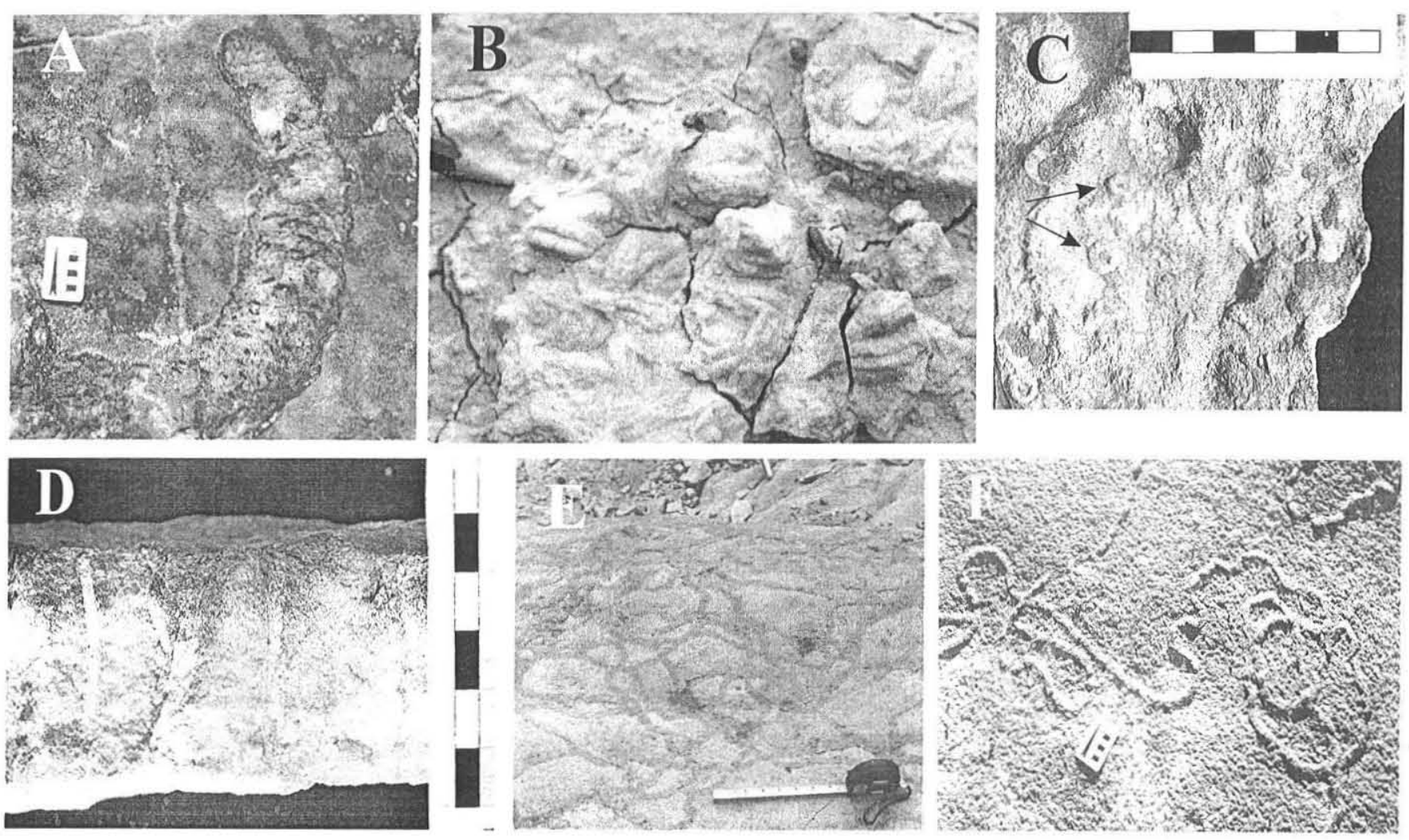

Figura 7 - Icnofósseis da Formação Piribebui. A - Rhizocorallium cf. irregulare preservado como epirrelevo em arenitos da fácies 10, afloramento 6 da figura I. Graduação da escala $=5 \mathrm{~cm}$. B - Rusophycus isp. preservado como hiporrelevo positivo, afloramento 1. C -Vista em planta de Skolithos linearis em arenitos da fácies 9, afloramento 3. Graduação da escala = 6 cm. D - Vista em corte vertical de Skolithos linearis em arenitos da fácies 9, afloramento 3. Graduação da escala = 6 cm. E Thalassinoides isp. em arenitos da fácies 10, afloramento 6. Porção estendida da trena $=8 \mathrm{~cm}$. F - Tubos sinuosos preservados como en:-velevo positivo em arenitos da fácies 10, afloramento 6.

\section{Referências}

Assine M.L.1996. Aspectos da estratigrafia das sequiências précarboníferas da Bacia do Paraná no Brasil. São Paulo. Tese de Doutoramento, Instituto de Geociências, Universidade de São Paulo, 207 pp..Assine M.L. 2001. O ciclo Ordoviciano/ Siluriano na Bacia do Paraná e correlação em outras bacias Gondwânicas. In: Melo J.H. \& Terra G.J.G. (eds) Correlação de Sequiências paleozóricas sul-americanas. Rio de Janeiro, PETROBRAS/CENPES, Série Ciência-Técnica-Petróleo-Seção Exploração de Petróleo 20:9-17.

Assine M. L.,Soares, P. C.. Milani E. J. 1994. Sequiências tectonosedimentares mesopaleozóicas da Bacia do Paraná, Sul do Brasil. Rev: Bras. Geoc., 24(2):77-89.

Assine M. L., Perinotto J. A., Alvarenga C. J. S., Petri S. 1998. Arquitetura estratigráfica, tratos deposicionais e paleogeografia da Bacia do Paraná (Brasil) no neo-ordoviciano/eo-siluriano. Rev. Bras. Geoc., 28(1):61-76.

Bigarella J.J.. Comte D. 1969. O Grupo Caacupé e sua importância na paleogeografia do Siluriano Sul-americano. Boletim da Sociedade Brasileira de Geologia 18(1):31-37.

Billings E. 1862. New species of fossil from different parts of Lower, Middle and Upper Silurian rocks of Canada. In: Paleozoic Fossils, Vol. 1. Geological Survey of Canada.

Blair T.C. \& McPherson J.G. 1994. Alluvial fans and their natural distinction from rivers based on morphology, hydraulic processes, sedimentry processes and facies assemblages. $J$. Sedim. Res., 64:450-489

Crimes T.P. 1970. Trilobite tracks and other trace fossils from the Upper Cambrian of North Wales. Geol. Journ.7:47-68.

DeGraff J.M. 1985. Late mesozoic crustal extension and rifting on the western edge of the Paraná Basin, Paragay. GSA Abstracts with Programs, 17:560.

Eckel E.B. 1959. Geology and mineral resources of Paraguay: a reconnaissaice. USGS Professional Papers 327.1-110.

Ehrenberg C.G. 1944. Ergänzende Bemerkungen zu den seinerzeit aus dem Miozän von Burgschleinitz beschiebenen Gangkernen und Bauten dekapoder Krebse. Paläont. Zeitschrift 23:354-359.

Fryberger S.G. \& Schenk C. J. 1988. Pin stripe lamination: a distinctive feature of modern and ancient eolian sediments. In: P. Hesp \& Fryberger S.G. (eds): Eolian Sediments. Sedim. Geol., 55:1-15.

Fürsich F.T. 1974. Ichnogenus Rhizocorallium. Paläont. Zeitschrift 48:16-28.

Gray J., Boucot A.J.T., Grahn Y., Himes G. 1992. A new record of carly Silurian land plant spores from Paraná Basin, Paraguay (Malvinokaffric Realm). Geological Magazine 12(6):741-752. 
Litoestratigrafia, sistemas deposicionais e icnofósseis do Grupo Caacupé, (Ordoviciano da Bacia do Paraná) na Cordilheira de los Altos, Paraguai Oriental

Hall J. 1852. Palaeontology of New York. Volume I. Containing Descriptions of the Organic Remains of the Lower Devonian System (Equiralent in Part to the Middle Silurian Rocks of Europe). 362 p. Benthuysen, Albany, N.Y.

Haldemann S.S. 1840. Supplement to number one of "A monograph of the Limniades, and other fiesh-water anivelve shells of North America" containing descriptions of apparently new animals in different classes, and the names and charaters of the subgnera in Paludina and Anculosa. 3 p. Philadelphia.

Harrington H.J. 1950. Geología del Paraguay Oriental. Contribuiciones Cintíficas. Serie E: Geologia. Facultad de Ciencias Exactas, Fisicas y Naturales. Universidad de Buenos Aires. 82 p.

Harrington H.J. 1956. Paraguai. In: Jenks (ed.). Handbook of South Americal (ienology. (iSA 65:9)-114.

Harrington H.J. 1972. Silurian of Paragualy. In: W.B.N. Berry \& A.J. Boucot (eds). Correlation of South American Silurian Rocks.GSA Special Publication, 143:41-50.

Mángano M.G., Buatois L.A., Aceñolaza G.F. 1996. Trace fossils and sedimentary facies from Late Cambrian - Early Ordovician tidedominated shelf (Santa Rosita Formation, northwest Argentina): Implications for icnofacies models of shallow marine successions. Ichmos 5:5.3-81.

Mayer G. 1954. Neue Bebachtungen an Lebenspurren aus dem unteren Hauptmuschelkalk (Trochitenkalk) von Wiasloch. Nenes. Jahrb. Geol. Paläont.. Abhandlungen 99:223-229.

Milani E.J. 1997. Evoluşão tectono-estratigráfica da Bacia do Paranci e

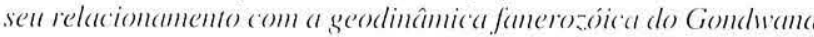
sul-ocidental. TTese de Doutoramento, Instituto de Geociências, Universidade Federal do Rio Grande do Sul.

Milani E.J. \& Ramos V. A. 1998. Orogenias Paleozóicas no domínio sulocidental do Gondwana e os ciclos de subsidência da Bacia do Paraná Re': Bras: Gieoc.. 28(4):47.3-484.

Moreira. M. I. C. \& Borghi L. 1999. Revisão estratigráfica do intervalo Ordoviciano-Siluriano da Bacia do Paraná. Anciis Acad. Bras. Ciênc., 71:743-766

Nicholson H.A. 1873. Contributions to the study of the errant annelids of the older Paleozoic rocks. Geol. Mag., 10:309-310.

Núñez M.E.G., Bartel W., Lahner L., Wiens F. 1998". Mapa Geologico de la Republica de Paraguay - Hoja Paraguarí. Texto Explicativo. Dirección de Recursos Minerales (MOPC). Instituto Federal de Geociências y Recursos Naturales (BGR). Assunción. 42 p.

Núñez M.E.G.. Lahner L., Muff R.,Wiens F. 1998". Mapa Geologico de la Republicar de Paraguay - Hoja San Jose. Texvo Exylicativo. Dirección de Recursos Minerales (MOPC). Instituto Federal de Geociências y Recursos Naturales (BGR). Assunción. 42 p.

d’Orbigny A. 1842. Vovage danss l'Amérique méridionale (le Brésil, la République oriental de l'Uruguav, la République Argentine, la Patagonie, la République du Chili. la République de Bolivia, la Républicue du Peru) exécuté pendant les annes 1826, 1827, 1829. 1830, 1831, 1832, et 1833. v:6, pt. 4 (Paléontologie). Pitois-Levrault,
Paris.

Orué D. 1998. Síntese da geologia do Paraguai Oriental, com ênfase para o magmatismo alcalino asssociado. Dissertação de Mestrado. Instituto de Geociências, Universidade de São Paulo. 162p. (inédito).

Pemberton S.G., Frey R.W. 1982. Trace fossil nomenclature and the Planolites-Palaeophycus dilemma. J. Paleont., 56:843-881.

Pemberton S.G., MacEachen J. A., Frey R.W. 1992. Trace Fossil Facies Models: Environmental and Allostratigraphic Significance. In Walker; R. G., and James, N. P. (eds.), Facies Models: Response to Sea Level Change. Geological Society of Canada, p. 47-72.

Pereira E., Bergamaschi S., Rodrigues M. A. 1998. Sedimentary evolution of the Ordovician, Silurian and Devonian sequences of Paraná Basin in Brazil. Zentralb. Geol. Paläont., Teil I 1997 (3-6):779-792.

Pereira E. 2000. Evolução tectono-sedimentar do intervalo ordovicianodevoniano da Bacia do Paraná com ênfase na sub-bacia do Alto Garças e no Paraguai oriental. Tese de Doutoramento, Instituto de Geociências, Universidade de São Paulo, 276 pp..

Putzer H. 1962. Die geologie von Paraguai. Beitr. Reg. Geol. Erde, 2: 1182.

Seilacher, A. 1955. Spurren und Fazies im Unterkambrium. In: Schindewolf, O.H. \& Seilacher, A. Beiträge zur Kenntniss des Kambriums in der Salt Range (Pakistan). Akademie der Wissenschaften und der Literatur; Mainz. Abhandlungen der Mathematisch-Naturwissenschafflichen Klasse 1955, 373-399.

Seilacher A. 1967. Bathymetry of trace fossils. Marine Geology, 5:413428.

Velázquez V.F., Riccomini C., Gomes C.B., Figueiredo L., Figueiredo C. 1998. Relações tectônicas do magmatismo alcalino do Paraguai Oriental. Revv. Instit. Geológ. São Paulo, 19:43-49.

Visser M.J. 1980. Neap-spring cicles reflected in Holocene subtidal largescale bedform deposits: a preliminary note. Geology, 8:543-546.

Walker R.G. 1975. Conglomerate: Sedimentary structures and facies models. In: Depositional Environments as Interpreted from Primary Sedimentary Structures and Stratification Sequences. Soc. Econ. Paleont. Miner., Short Course Notes 2, pp.:133-161.

Webby B.D. 1970. Late Precambrian trace fossils from New South Wales. Lethaia, 3:79-109.

Wolfart R. 1961. Stratigraphie und Fauna des älterer Paläozoikuns (Silur:/ Devon.) in Paraguay. Geol. Jahrbuch., 78:29-102.

Zenker J.C. 1836. Historich-topographisches Taschenbuch von Jena und seiner Umgebund besonder in naturwissenschaftlicher und medicinischer Beriehung. 338 p. Wackenhoder:

Manuscrito A-1453

Recebido em 28 de julho de 2003

Revisão dos autores em 20 de abril de 2004 Revisão aceita em 05 de maio de 2004 